\title{
Angiotropic intravascular large-cell lymphoma with massive cerebral extension
}

\author{
R Torenbeek, Ph Scheltens, R J M Strack van Schijndel, P R Algra, J J Heimans, \\ $P$ van der Valk
}

\begin{abstract}
Angiotropic intravascular large-cell lymphoma (AILL) is a rare, generally fatal disease characterised by a multifocal proliferation of neoplastic mononuclear cells within small blood vessels. The diagnosis of a patient was made at necropsy. The malignant cells had infiltrated the periventricular areas of the brain.
\end{abstract}

(F Neurol Neurosurg Psychiatry 1993;56:914-916)

Angiotropic intravascular large-cell lymphoma (AILL) is an uncommon entity characterised by a massive neoplastic proliferation of mononuclear cells within the lumina of small and intermediate sized vessels. This condition was first reported under the designation of "angioendotheliomatosis proliferans systemata". " Later various terms, such as "neoplastic angioendotheliomatosis", "malignant angioendotheliomatosis", "proliferating endotheliosis", and "systemic angioendotheliomatosis" 23 have been used to describe this rare clinicopathological entity. Initially this process was thought to be a neoplasm of endothelial origin, but immunopathological and morphological evidence now supports a lymphoid origin. ${ }^{4}$

Vascular occlusions in a variety of organs can produce a bewildering array of clinical symptoms. Most commonly, patients with AILL present with bizarre neurological manifestations. Because the disease is rare and there are no specific diagnostic procedures apart from cerebral biopsy, it can be difficult to diagnose during life, and in most cases the diagnosis is made after necropsy.

\section{Case report}

A 62 year old woman was admitted because of weight loss, fatigue, nausea and vomiting.

A few days after admission the patient complained of diplopia. She was bradyphrenic, and had bilateral internuclear ophthalmoplegia and horizontal nystagmus on upward gaze.

MRI showed bilateral periventricular white matter lesions in both frontal lobes. The white matter abnormalities consisted of large confluent lesions of high signal intensity on T2-weighted spin echo images. Transverse T2-weighted images showed involvement of the thalamus, globus pallidus and brainstem. After intravenous administration of Gado- linium DTPA areas of abnormal increased signal intensity were seen around the lateral, third and fourth ventricles. There was no abnormal enhancement of the leptomeninges (fig 1).

CSF examination repeatedly revealed an elevated cell count $(224 / \mu 13$; $90 \%$ lymphocytes and $10 \%$ monocytes) and an elevated protein content $(1263 \mathrm{mg} / \mathrm{l})$. The glucose level was $2.4 \mathrm{mmol} / 1$ (serum $5.9 \mathrm{mmol} / \mathrm{l}$ ). Antibody titres against neurotropic viruses, CSF cultures and Ziehl-Neelson stains were negative. She was treated as for tuberculous meningitis without benefit. She developed hypoventilation and coma. The MRI showed progression of the periventricular and brainstem lesions. CSF examinations showed pleocytosis, but no specific abnormalities, and especially no malignant cells. Mechanical ventilation was started and dexamethasone 12 $\mathrm{mg}$ per day added. Over a period of 24 hours the patient regained conciousness but remained dependent on mechanical ventilation. At this point the CSF contained tumour cells. Because of her very poor clinical condition no further treatment was started. The patient died of pneumonia after 28 days of mechanical ventilation.

\section{Materials and methods}

A complete necropsy was conducted. Formalin (5\%) fixed, paraffin embedded

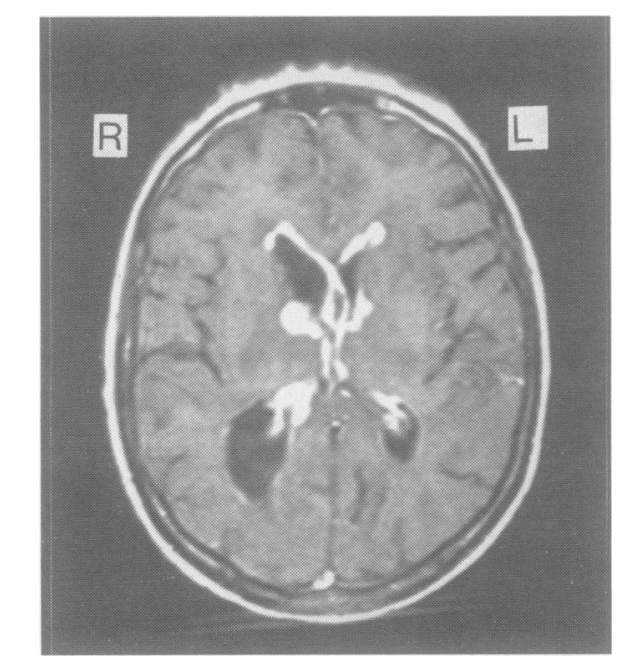

Figure 1 Bilateral confluent lesions periventricular in frontal white matter; tumour mass is revealed as high signal intensity lesion, and oedema as low signal intensity lesion. (T1 weighted images, after intravenous contrast administration). 
tissue obtained at necropsy was examined histologically with a variety of stains including hematoxylin and eosin, periodic-acid Schiff, Gomori's reticulin, Van Gieson's elastin and chloroacetate esterase.

Immunoperoxidase stains were performed using monoclonal antibodies against leucocyte common antigen (LCA) (leucocytes), MT1 ( $T$ lymphocytes monocytes, granulocytes), UCHL1 (Subset of T lymphocytes), MB2 (B lymphocytes, endothelial cells), L26 (majority of B lymphocytes), LeuM1 (neutrophyllic granulocytes), Vimentin (cells of mesenchymal origin), polykeratin (cells of epithelial origin) and Factor VIII related antigen (endothelial cell differentiation).

Primary antibodies were then applied for one hour at room temperature (MT1 and MB2 24 hours at $4^{\circ} \mathrm{C}$ ) in moisture chambers. Sections to be labelled with anti polykeratins, LCA, UCHL1 and MT1 were first digested with $0.5 \%$ trypsin in phosphate buffered

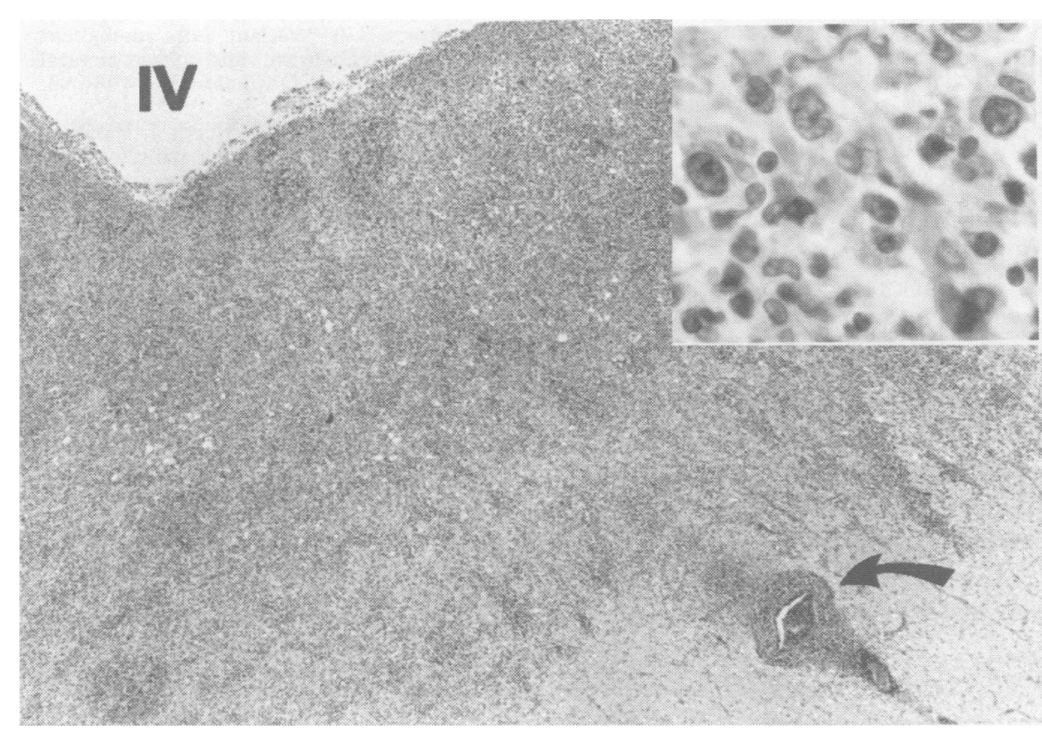

Figure 2 AILL localised in brain parenchyma around the fourth ventricle (IV), and in intracerebral vessels (arrow). (Inset: neoplastic cells with scanty amphophilic cytoplasm, polymorphic hyperchromatic nuclei).

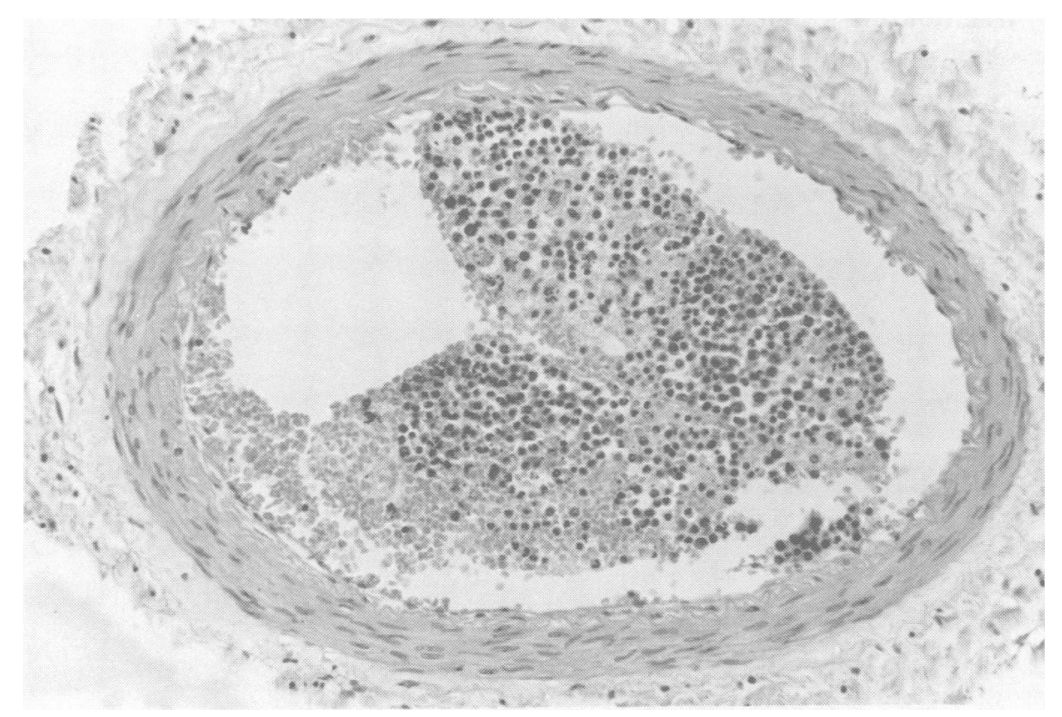

Figure 3 Localisation of AILL in the anterior spinal artery $(H \mathcal{E} E \times 200)$. saline $(\mathrm{pH} 7 \cdot 4)$ for 30 minutes at room temperature. This step was not employed for other immunostains. After incubation with the specific antibody, the biotinylated Goatanti-Mouse IgG was followed; after washing avidin-biotin-peroxidase complex was added. Sections were developed with diaminobenzidine for three minutes, counterstained with hematoxylin, and mounted with depex.

\section{Pathological findings}

At necropsy, no macroscopic abnormalities were found except for massive bilateral bronchopneumonia.

The brain was examined after fixation, and on cut surface showed multiple white lesions around the ventricles and periaqueductal grey substance. The lesions extended into the basal ganglia, the hypothalamus, and the nuclei in the tegmentum pontis (fig 2).

On histological examination, almost all organs (heart, lungs, thyroid, liver, pancreas, kidney, adrenal glands, para-aortic lymph nodes, uterus and bladder wall) contained numerous dilated vessels of various sizes which showed partial or complete occlusion by proliferating neoplastic mononuclear cells, without evidence of cohesion or syncytial aggregation (fig 3). The neoplastic cells were generally large and had scanty amphophilic cytoplasm. The hyperchromatic nuclei were variable in size, irregular in shape with wrinkled, irregular nuclear membranes. They had clumped chromatin and one or several relatively prominent nucleoli. Mitotic figures were found easily. The cells showed immunohistochemical reactivity for LCA, L26, MB2 and Vimentin. No expression of LeuM1, MT1, UCHL1, cytokeratin and Factor VIII related antigen was found. Endothelial cells showed no pleomorphism or atypia. In part of the brain, neoplastic cells were found within the lumina of vessels, adhering to the endothelial cells. In periventricular locations, along the CSF pathways, tumour cells were found outside the vessels, within the brain parenchyma. Here, a perivascular arrangement was sometimes seen. The proliferation destroyed pre-existent structures, among them the hypothalamic nuclei. The cells were histologically and immunohistochemically the same as seen in the vessels elsewhere in the body.

\section{Discussion}

Clinically, AILL is a difficult disease to diagnose. Bizarre neurological manifestations, such as global encephalopathy, dementia, bradyphrenia, confusional states, or altered consciousness $^{5}$ are often predominant, but review of the reported cases reveals additional dermatological, ${ }^{16}$ ophthalmological ${ }^{7}$ and isolated lung and adrenal gland involvement. ${ }^{8-11}$ Infrequently, CNS involvement is occult and only discovered at necropsy.

Thirty nine patients have been described in the English literature initially presenting with neurological abnormalities. There were 23 
males and 16 females and both the median and average ages of onset were 63 years with a range of 41-79 years. The disease was fatal in 36 cases, the median survival from onset of symptoms was seven months. The longest surviving patient lived nine years, but only seven patients survived longer than 16 months. Among those 39 patients 19 were diagnosed during life, and 12 received chemotherapy other than corticosteroid hormones. One received brain irradiation and another received whole body irradiation. The prognosis of angiotropic intravascular largecell lymphoma can therefore be considered dismal, even in those cases that were diagnosed premortem, and in which treatment was attempted. ${ }^{12}$ Possible survival is more related to the extent of dissemination. Because the disease is very rare and lacks specific diagnostic features, the diagnosis is infrequently established before necropsy. A remarkable discrepancy exists in many cases (ours included) between the -isolated- neurological symptoms, and the abundant presence of intravascular tumour cells plugging vascular lumina of almost every organ. Skin, muscle and cerebral biopsies have been taken and transbronchial biopsies have been suggested to reach the diagnosis, ${ }^{12-15}$ but since AIILL is a lymphoma with the propensity to localise and proliferate throughout the body, a biopsy of any organ showing dysfunction or abnormalities may be diagnostic. Remarkably, neoplastic cells have not been reported in CSF. ${ }^{5}$

Routine radiological investigation is generally non diagnostic. However, the contribution of MRI analysis may be more substantial, but has been reported only rarely. ${ }^{16}$ The macroscopic abnormalities of the brain were consistent with the MRI examination. The large, confluent periventricular and white matter lesions of high signal intensity on T2weighted images and a high signal intensity after intravenous contrast administration corresponded to lymphomatous tissue and oedema.

The characteristic histological pattern of AILL, shows distended vascular spaces with intraluminal cells, some appearing adherent to the endothelium, some "free floating". The neoplastic cells are generally large and, in cases where immunohistochemistry was performed, have been proved to be of B-cell origin. ${ }^{4}$ Perivascular parenchymatous foci of neoplastic cells are frequently seen, but extensive extravascular spread was only once reported in the kidneys. ${ }^{5}$ Our case was unique in that there was a massive parenchymatous extension of tumour in the brain, especially in the periventricular region.

1 Pfleger L, Tapperner J. Zur Kenntnis der systemisierter Endotheliomatose der cutanen Blutgefässe. Hautartz 1959;10:359-63.

2 Fulling KH, Gersell DJ. Neoplastic angioendotheliomatosis: histologic, immunohistochemical and ultrastructural findings in two cases. Cancer 1983;51:1107-18.

3 Wick MR, Mills SE, Scheithaue BW, Cooper PH, Davitz MA, Parkinson K. Reassesment of "malignant angioendotheliomatosis". Am $¥$ Surg Pathol 1986;10:112-23.

4 Sheibani K, Battifora H, Winberg CD, et al. Further evidence that "malignant" angioendotheliomatosis" is an angiotropic lymphoma. $N$ Engl f Med 1986;314:943-8.

5 Smadja D, Mas J-L, Fallet-Bianco C, et al. Intravascular lymphomatosis (neoplastic angioendotheliosis) of the central nervous system: case report and literature review. $\mathcal{F}$ Neuro-oncology 1991;11:171-80.

6 Willemze R, Kruyswiik MR, De Bruin CD, Meijer CJLM, Van Berkel W: Angiotropic (intravascular) large cell lymphoma of the skin previously classified as malignant lymphoma of the skin previously classifed as malignant

angioendotheliomatosis. Br f Dermatol 1987;116:393-9. angioendotheliomatosis. A variant of malignant angioendotheliomatosis. A variant of malignant observations of three cases. Ophthalmology 1986;93: 1237-45.

8 Stroup RM, Sheibani K, Moncada A, Purdy J, Battifora $\mathrm{H}$ : Angiotropic (intravascular) large cell lymphoma: A clinicopathologic study of seven cases with unique clinical presentation. Cancer 1990;66:1781-8.

9 Yousem SA, Hoghholzer L. Unusual thoracic manifestations of epitheliod hemangioma. Arch Pathol Lab Med 1987:11;459-63.

10 Yousem SA, Colby TV. Intravascular lymphomatosis presenting in the lung. Cancer 1990;65:349-53.

11 Nakagawa N, Takahashi M, Maeda K, Fujimura N, Yufu $M$. Case report: adrenal haemangioma coexisting with malignant haemangioendothelioma. Clin-Radiol 1986; malignant

12 Williams DB, Lyons MK, Yanagihara $T$, Colgan JP, Banks PM. Cerebral angiotropic large cell lymphoma (neoplastic angioendotheliamatosis): therapeutic considerations. I Neurol Sciences 1991:103:16-21.

13 Roraque HG, Mandler RN, Griffey MS, Orrison WW, Kornfeld M. Neoplastic angioendotheliomatosis. Arch Neurol 1990;47:929-30.

14 Molina A, Lombard C, Donlon T, Bangs CD, Dorfman RF. Immunohistochemical and cytogenetic studies indicate that malignant angioendotheliomatosis is a primary intravascular (angiotropic) lymphoma. Cancer 1990;66: 474-9.

15 Pellicone JT, Goldstein HB. Pulmonary malignant angioendotheliomatosis. Presentation with fever and syndrom of inappropriate antidiuretic hormone. Chest syndrom of inapp

16 Daniel SE, Rodge P, Scaravilli F. Malignant angioendotheliomatosis involving the nervous system: support for the lymphoid origin of the neoplastic cells. $f$ Neurol Neurosurg Psychiatry 1987;50:1173-7. 